\title{
BUDAYA ORGANISASI, EFEKTIVITAS PENGENDALIAN INTERNAL DAN FRAUD
}

\author{
Susilawati(1), $\operatorname{Rr}$ Anggun Kartika Dewi ${ }^{(2)}$ \\ susilawati@stembi.ac.id ${ }^{(1)}$, anggunkartikadewi@gmail.com ${ }^{(2)}$ \\ (1) Dosen Program Studi Akuntansi STIE STEMBI - Bandung Business School, \\ Peneliti Junior STIE STEMBI ${ }^{(2)}$
}

\begin{abstract}
Ringkasan
Tujuan penelitian ini adalah untuk mengetahui seberapa besar budaya organisasi dan efektivitas pengendalian internal berpengaruh terhadap kecurangan (fraud). Unit analisisnya adalah Dinas Pemerintahan di Kota Bandung; Penulis menganalisis budaya organisasi dan efektivitas pengendalian internal pada 21 Dinas Kota Bandung menggunakan metode analisis deskriptif. Jenis data yang digunakan adalah data primer yang diambil menggunakan kuesioner. Data dianalisis dengan multiple regression. Temuan penelitian berhasil mengkonfirmasi bahwa budaya organisasi dan efektivitas pengendalian internal berpengaruh terhadap kecurangan/fraud. Implikasinya adalah, bahwa setiap Dinas Pemerintahan harus melakukan reformasi dalam memperbarui budaya organisasi dan meningkatkan efektivitas pengendalian internal untuk mengurangi tingkat kecurangan.
\end{abstract}

Kata kunci: Budaya Organisasi, Pengendalian Internal, Fraud.

\section{A. PENDAHULUAN}

Lembaga pemerintahan adalah lembaga yang melakukan pelayanan terhadap publik. Lembaga pemerintahan harus bersikap transparan dalam melakukan kegiatan pemerintahan. Munculnya kasus mengenai fraud yang terjadi pada lembaga pemerintahan akhir-akhir ini menjadi masalah yang sangat serius untuk diselesaikan. Banyak faktor-faktor yang menjadi penyebab terjadinya fraud pada lembaga pemerintahan. Beberapa faktor yang dapat menyebabkan terjadinya fraud adalah kurangnya efektivitas pengendalian internal dan bagaimana budaya etis organisasi dalam suatu lembaga pemerintahan tersebut terbentuk.

Pengendalian yang dirancang secara sistematik dapat mencegah adanya kekeliruan dan ketidakberesan. Pencegahan terjadi apabila pengendalian tersebut dapat mendeteksi adanya fraud pada suatu aktivitas tanpa menunggu adanya audit (Kayono, 2013:51). Apabila sistem pengendalian internal dapat berjalan dengan baik, maka hal ini dapat meminimalisir tindak kecurangan yang akan dilakukan oleh pihak-pihak yang akan memanfaatkan peluang ini untuk memperkaya dirinya. Budaya etis organisasi juga dapat mempengaruhi bagaimana sikap dan tindakan seseorang dalam suatu organisasi diatur. Mereka akan taat pada aturan yang berlaku dalam organisasinya.

Budaya organisasi yang buruk akan menimbulkan dampak yang buruk pula bagi pemerintahan, seperti pada kasus petugas kebersihan samsat subang yang tertangkap basah menjadi calo. Petugas kebersihan ini biasa menerima perintah dari $\mathrm{PHL}$ samsat subang untuk membantu warga yang ingin melakukan proses mutasi kendaraan atau melakukan perpanjangan STNK dari wajib pajak (Kombes Pol Yusri Yunus, 2016). Hal ini memperlihatkan bagaimana budaya organisasi yang tidak baik, dapat membuat celah-celah baru bagi para calo untuk melakukan perbuatan-perbuatan yang menyimpang yang tidak sesuai dengan peraturan yang berlaku di samsat subang.

Hal lain yang juga sedang menjadi sorotan adalah kasus pemecatan beberapa kepala sekolah favorit yang melakukan tindakan pungutan liar. Walikota bandung, Ridwan Kamil mengumumkan adanya skorsing, rekomendasi pemberhentian, hingga pemberhentian kepala sekolah di sejumlah sekolah mulai SD sampai SMA se-Kota Bandung. Ridwan Kamil menyebutkan, ada sekitar 19 sekolah yang dilakukan pemeriksaan dan mendapatkan bentuk-bentuk pelanggaran. Seperti melakukan penjualan kepada anak-anak sekolah mulai buku dan seragam yang tidak semestinya,untuk mendapatkan keuntungan yang tidak bisa dipertanggungjawabkan (Muhamad Nandri Prilatama, 2016). Para pelaku penyimpangan akan melakukan tindakan penyimpangan dimana mereka menemukan celah yang dapat mereka manfaatkan untuk melakukan tindakan kecurangan tersebut. bersikap Oleh sebab itu budaya etis organisasi sangat penting didalam suatu organisasi. 
Selain budaya organisasi, faktor lain yang mungkin menjadi penyebab terjadinya fraud adalah lemahnya pengendalian internal yang ada di instansi pemerintahan. Contoh permasalahan mengenai lemahnya pengendalian internal adalah masalah yang menimpa pada dunia pendidikan di kota Bandung. Kasus yang menimpa dunia pendidikan kota Bandung adalah mengenai pungutan liar yang terjadi di sekolah-sekolah. Hal ini dinyatakan oleh koordinator GMPP bahwa pendidikan di kota Bandung ini bukan hanya faktor kultur, tetapi lemahnya pengawasan bisa menjadi penyebab adanya tindakan pungli di sekolah-sekolah, sehingga seolah ada pembiaran pula dari Dinas Pendidikan Kota Bandung, menyebabkan tindakan ini merajalela (Harry Santoni:2016). Pernyataan koordinator GMPP tersebut jelas manyatakan bahwa pungli yang terjadi di sekolah-sekolah disebabkan oleh budaya organisasi yang tidak baik serta lemahnya pengendalian internal yang berbentuk pengawasan dalam kegiatan dunia pendidikan. Hal semacam ini jelas harus segera di benahi agar tindakan-tindakan penyimpangan tersebut dapat segera teratasi dan tidak terjadi kembali.

Kasus lain yang terjadi adalah mengenai laporan Ombudsman serahkan rekaman video praktik pungli di Bandung ke Ridwan Kamil. Ombudsman telah menyerahkan video rekaman yang diduga berpotensi terjadi pungutan liar atau praktik maladministrasi di lingkungan Pemkot Bandung. Menurut Khoirul, proses investigasi dilengkapi bukti visual itu dilakoni asisten Ombudsman yang menyambangi objek penelusuran yaitu tiga satuan kerja perangkat daerah (SKPD), tujuh kecamatan, dan delapan kelurahan. Ombudsman bergerak menyelisik problem pelayanan publik berupa pengurusan izin di kantor tersebut setelah menerima pengaduan dari masyarakat soal indikasi praktik pungli (Muhammad Khoirul Anwar, 2015).

Terungkapnya kasus mengenai pungli yang terjadi di dinas penanaman modal dan pelayanan terpadu satu pintu juga akhir-akhir ini menjadi sorotan publik. Kepolisian Resor Kota Besar (Polrestabes) Bandung telah menetapkan kepala dinas penanaman modal dan pelayanan terpadu satu pintu (DPMPTPS) kota bandung Dandan riza wardhana sebagai tersangka kasus pungutan liar (pungli) dan gratifikasi. Modus pungli yang dilakukan oleh dandan bersama lima anak buahnya adalah mempercepat pengeluaran perizinan tanpa melalui sistem online dan menyarankan pengajuan izin agar melalui sistem manual. Beberapa perizinan yang menjadi sasaran punglidandan bersama anak buahnya yakni pembuatan Surat Izin Usaha Perdagangan
(SIUP), Tanda Daftar Usaha Pariwisata (TDUP), Izin Mendirikan Bangunan (IMB), reklame dan izin lainnya (Putra Prima Perdana, 2017). Pernyataan ini di peroleh dari Kombes Pol Hendro Pandowo saat ditemui di Mapolresta Bandung. Kombes Pol Hendro Pandowo menyatakan dengan sistem manual mereka mendapatkan uang. Janjinya mempercepat perizinan dengan memberikan imbalan. Perizinan yang seharusnya terbit satu minggu lebih, dengan begini bisa satu atau dua hari (Kombes Pol Hendro Pandowo, 2017)..

Berdasarkan permasalahan tersebut, penulis ingin mengkaji dan melakukan penelitian mengenai pengaruh budaya organisasi, efektivitas pengendalian internal dan fraud pada kantor dinas se-Kota Bandung.

\section{B. LANDASAN TEORI}

Budaya organisasi menurut Alma (2012:305) merupakan sistem nilai dan kepercayaan yang dianut bersama oleh anggota organisasi yang membedakan organisasi itu dengan organisasi lainnya. Ada sepuluh aspek organisasi yang akan membentuk budaya organisasi, baik itu merupakan badan usaha, instansi pemerintah atau lembaga lainnya, yaitu:

1. Peraturan dan kebijakan

2. Tujuan dan ukuran

3. Kebiasaan dan norma

4. Pelatihan

5. Perilaku manajeman

6. Upacara dan kejadian

7. Penghargaan dan pengakuan

8. Komunikasi

9. Lingkungan

10.Struktur organisasi

Pengendalian internal adalah suatu proses, yang dipengaruhi oleh dewan komisaris, manajemen, dan personel lainnya dalam suatu entitas, yang dirancang untuk memberikan keyakinan memadai guna mencapai tujuan-tujuan yaitu keandalan pelaporan keuangan, menjaga kekayaan dan catatan organisasi, kepatuhan terhadap hukum dan peraturan, efektivitas dan efisiensi operasi (Rahayu dan Ely, 2010 : 21). Adapun suatu pengendalian internal menurut COSO dalam Hery (2013:167) harus terdiri dari lima komponen yaitu :

1. Lingkungan pengendalian. Tanpa lingkungan pengendalian yang efektif, keempat komponen lainnya mungkin tidak akan menghasilkan pengendalian internal yang efktif. Lingkungan pengendalian internal berfungsi sebagai payung bagi keempat komponen pengendalian internal lainnya. 
Lingkungan pengendalian terdiri atas tindakan, kebijakan, dan prosedur yang mencerminkan sikap manajemen puncak, direktur, dan pemilik atas entitas secara keseluruhan mengenai pengendalian internal serta arti pentingnya entitas tersebut.

2. Penetapan resiko manajemen. Merupakan tindakan yang dilakukan manajemen untuk megidentifikasi dan menganalisis resikoresiko terkait penyusunan laporan keuangan yang sesuai dengan prinsip-prinsip akuntansi yang berlaku umum.

3. Aktivitas pengendalian. Merupakan kebijakan dan prosedur untuk membantu memastikan bahwa tindakan yang diperlukan untuk mengatasi resiko telah diambil guna mencapai tujuan entitas. Kebijakan dan prosedur tersebut terdiri dari hal-hal berikut :
a. Pemisahan tugas
b. Otorisasi yang tepat atas transaksi
c. Dokumen dan catatan yang memadai
d. Pengendalian fisik atas aktiva dan catatan
e. Pemeriksaan independen atau verifikasi internal

4. Informasi dan komunikasi akuntansi

5. Pemantauan

Karyono (2013:1) memberikan definisi mengenai kecurangan yang merupakan tindakan melawan hukum yang merugikan entitas/organisasi dan menguntungkan pelakunya. Tindak kecurangan itu berupa pengambilan atau pencurian harta milik atau aset organisasi, menyembunyikan dan mengalihkan atau membelanjakan aset tersebut dari luar organisasi dan dapat dilakukan oleh manajemen dan karyawan.

Association of Certified Fraud Examinations (ACFE), salah satu asosiasi di USA yang mempunyai kegiatan utama dalam pencegahan dan pemberantasan kecurangan, mengkategorikan kecurangan dalam tiga kelompok sebagai berikut:

1. Pernyataan Palsu atau Salah Pernyataan (Fraudulent Statement)

Fraudulent statement meliputi tindakan yang dilakukan oleh pejabat atau eksekutif suatu perusahaan atau instansi pemerintah untuk menutupi kondisi keuangan yang sebenarnya dengan melakukan rekayasa keuangan (financial engineering) dalam penyajian laporan keuangannya untuk memperoleh keuntungan atau mungkin dapat dianalogikan dengan istilah window dressing. Kecurangan ini dapat bersifat finansial atau kecurangan non finansial.

2. Penyalahgunaan Aset (Asset Misappropriation)

Asset misappropriation adalah penyalahgunaan/pencurian/pengambilan aset atau harta perusahaan atau pihak lain. Jenis-jenis Penyalahgunaan Aset (Asset Misappropriation) antara lain Larceny, Billing Schemes, Payroll schemes, Expense Reimbursement schemes, Check Tampering, dan Register Disbursements.

3. Korupsi (Corruption)

Jenis kecurangan ini banyak terjadi di sektor pemerintahan. Kecurangan dalam bentuk korupsi ini sulit untuk dideteksi karena dilakukan oleh beberapa orang yang berkerjasama dalam melakukan kecurangan tersebut. Menurut ACFE, korupsi terbagi ke dalam pertentangan kepentingan (conflict of interest), suap (bribery), pemberian illegal (illegal gratuity), dan pemerasan (economic extortion).

\section{METODE PENELITIAN}

Objek dalam penelitian ini adalah budaya organisasi, efektifitas pengendalian internal dan kecurangan (Fraud); Unit analisis dalam penelitian ini adalah dinas pemerintahan di Kota Bandung; Penulis menganalisis budaya organisasi dan efektivitas pengendalian internal pada 21 dinas Pemerintah Kota Bandung menggunakan metode analisis deskriptif. Jenis data yang digunakan dalam penelitian ini adalah data primer; Metode yang digunakan dalam penelitian ini adalah metode penelitian kuantitatif.

\section{HASIL DAN PEMBAHASAN}

Analisis data pada penelitian ini menggunakan teknik analisis regresi linear berganda. Hasil dari pengujian dengan alat statistik dapat dilihat pada table 4.1 berikut ini :

Tabel 4.1

Coefficients $^{a}$

\begin{tabular}{|c|c|c|c|c|c|c|c|}
\hline \multirow[b]{2}{*}{ Model } & \multicolumn{2}{|c|}{ Unstandardized Coefficients } & \multirow{2}{*}{$\begin{array}{c}\begin{array}{c}\text { Standardized } \\
\text { Coefficients }\end{array} \\
\text { Beta }\end{array}$} & \multirow[b]{2}{*}{$t$} & \multirow[b]{2}{*}{ Sig. } & \multicolumn{2}{|c|}{ Collinearity Statistics } \\
\hline & B & Std. Error & & & & Tolerance & VIF \\
\hline
\end{tabular}




\begin{tabular}{|l|r|r|r|r|r|r|r|}
\hline 1 (Constant) & 18.176 & 2.721 & & 6.679 & .000 & & \\
$\mathrm{X} 1$ & -.174 & .147 & -.316 & -1.186 & .251 & .466 & 2.146 \\
$\mathrm{X} 2$ & -.228 & .167 & -.366 & -1.370 & .187 & .466 & 2.146 \\
\hline
\end{tabular}

a. Dependent Variable: $Y$

Dari table 4.1 menunjukan persamaan regresi linear berganda yaitu sebagai berikut :

$$
Y=18.176-0.174 X_{1}-0.228 X_{2}
$$

Dari persamaan regresi diatas dapat dilihat bahwa koefisien regresi $\left(B_{i}\right)$ untuk variabel Budaya Organisasi dan Efektivitas Pengendalian Internal berpengaruh negatif (-) terhadap Kecurangan (Fraud).

Variabel Budaya Organisasi memiliki nilai koefisien regresi $\left(B_{i}\right)$ sebesar 0.174 . Hal ini menunjukan bahwa setiap peningkatan variabel budaya organisasi satu satuan nilai akan menurunkan Kecurangan/fraud (Y) sebesar $17,4 \%$ satuan nilai, dengan asumsi variabel lainnya nol.

Variabel Efektifitas Pengendalian Internal memiliki nilai koefisien regresi $\left(B_{i}\right)$ sebesar 0.228. Hal ini menunjukan bahwa setiap peningkatan variabel Efektifitas Pengendalian Internal satu satuan nilai akan menurunkan Kecurangan / fraud sebesar $22,8 \%$ satuan nilai, dengan asumsi variabel lainnya nol.

Berdasarkan hasil perhitungan yang terlihat pada tabel 4.1 diatas di peroleh nilai tabel pada taraf nyata $(\alpha) 0.05$ dengan nilai $t_{\text {tabel }}=\mathrm{t}$ $(\alpha / 2 ; n-k-1)=0,025 ; 18)=2.101$. Nilai $t_{\text {hitung }}$ dibandingkan dengan nilai $t_{\text {tabel }}$ menghasilkan simpulan bahwa secara parsial budaya organisasi mempengaruhi kecurangan secara tidak signifikan dan secara parsial efektivitas pengendalian internal mempengaruhi kecurangan secara tidak signifikan.

\section{Pengujian selanjutnya adalah} pengujian atas hipotesis sebagai berikut:

$\mathrm{H}_{0}$ : Tidak terdapat pengaruh Budaya Organisasi dan Efektivitas Pengendalian Internal terhadap Kecurangan /fraud

$\mathrm{H}_{1}$ : Terdapat pengaruh Budaya Organisasi dan Efektivitas Pengendalian Internal terhadap Kecurangan /fraud

Untuk mengetahui seberapa besar pengaruh kedua variabel independen tersebut secara simultan terhadap variabel dependen adalah dengan melakukan pengujian dengan koefisien determinasi $\left(R^{2}\right)$. Dari hasil pengujian, diperoleh nilai koefisien determinasi $\left(R^{2}\right)$ persamaan regresi yaitu sebesar 0.403 (nilai RSquare) yang disajikan pada table berikut ini:

Tabel 4.2

Model Summary

\begin{tabular}{|l|r|r|r|r|r|}
\hline Model & $\mathrm{R}$ & \multicolumn{1}{|c|}{ R Square } & $\begin{array}{c}\text { Adjusted R } \\
\text { Square }\end{array}$ & $\begin{array}{c}\text { Std. Error of the } \\
\text { Estimate }\end{array}$ & \multicolumn{1}{c|}{ Durbin-Watson } \\
\hline 1 & $.635^{\mathrm{a}}$ & .403 & .337 & 2.11744 & 1.716 \\
\hline
\end{tabular}

a. Predictors: (Constant), X2, X1

b. Dependent Variable: $Y$

Berdasarkan tabel 4.2 tersebut, secara bersama-sama bahwa budaya organisasi dan efektivitas pengendalian internal memberikan pengaruh sebesar $40.3 \%$ terhadap kecurangan/fraud. Angka 0.403 disini artinya setiap perubahan kecurangan sebesar $40.3 \%$ dipengaruhi oleh variabel budaya organisasi dan efektifitas pengendalian internal. Adapun sebesar $59.7 \%$ sisanya disebabkan oleh variabel-variabel lain diluar variabel yang tidak diteliti. 
ANOVA $^{D}$

\begin{tabular}{|ll|r|r|r|r|r|}
\hline Model & & Sum of Squares & Df & Mean Square & F & Sig. \\
\hline 1 & Regression & 54.465 & 2 & 27.232 & 6.074 & $.010^{a}$ \\
& Residual & 80.704 & 18 & 4.484 & & \\
Total & 135.168 & 20 & & & \\
\hline
\end{tabular}

a. Predictors: (Constant), $\mathrm{X} 2, \mathrm{X} 1$

b. Dependent Variable: $Y$

Berdasarkan hasil perhitungan yang terlihat pada tabel 4.3 diatas di peroleh nilai $F_{\text {tabel }}$ pada taraf nyata (a) 0.05 dengan derajat bebas $V_{1}=k ; V_{2}=k ; V_{3}=n-k-1=21-2-1=18$ ialah 3.16. Nilai $F_{\text {hitung }}$ dibandingkan dengan nilai $F_{\text {tabel }}$ menghasilkan simpulan bahwa pengaruh budaya organisasi dan efektivitas pengendalian internal mempengaruhi kecurangan secara signifikan.

\section{E. PENUTUP \\ Kesimpulan}

Simpulan yang dapat diambil dari penelitian ini adalah budaya organisasi dan efektivitas pengendalian internal berpengaruh negatif terhadap kecurangan (Fraud). Artinya semakin baik budaya organisasi dan efektivitas pengendalian internal di dinas kota Bandung akan mampu menurunkan tingkat kecurangan (fraud).

\section{Saran}

1. Dinas menerapkan peraturan secara efektif, kebijakan yang memadai, tujuan yang terarah, pelatihan yang efektif, dan struktur organisasi yang jelas untuk meningkatkan kinerja pegawai dan perilaku manajemen yang baik.

2. Dinas memberikan penghargaan kepada pegawai yang berprestasi; dan menciptakan lingkungan kerja yang kondusif.

3. Dinas mengatasi kecurangan (Fraud) dengan menerapkan lingkungan pengendalian, menetapkan resiko manajemen, aktivitas pengendalian, pemantauan, informasi dan komunikasi.

\section{F. DAFTAR PUSTAKA}

1. Adinda, Yanita Maya. 2015. Faktor-faktor yang mempengaruhi terjadinya kecurangan (fraud) di sektor pemerintahan kabupaten klaten. Semarang : Universitas Negeri Semarang

2. Alma, Buchari. 2012. Pengantar Bisnis. Bandung : Alfabeta, CV

3. Amaliah, Lisna. 2015. Pengaruh penerapan pengendalian internal dan fungsi auditor internal terhadap pencegahan kecurangan. Bandung : Stembi

4. Amrizal. 2004. Pencegahan dan pendeteksian kecurangan oleh internal auditor. Jakarta: Direktorat Investigasi BUMN dan BUMD Deputi Bidang Investigasi

5. Arens, Alvin A. Et al. 2008. Auditing dan Jasa Assurance: Pendekatan Terintegrasi. Jilid Satu. Edisi Keduabelas. Jakarta: Erlangga

6. Arens, A. A., J., Elder, Mark S. B. 2004. Auditing and Assurance Service an Integrated Approach. New Jersey: Prentice Hall International

7. Arens, Alvin A, dkk. 2015. Auditing dan Jasa Assurance : Pendekatan Terintegrasi. Jilid Satu. Edisi Kelimabelas. Jakarta: Erlangga

8. Daft, Richard L. 2010. Era Baru Manajemen. Buku 1. Edisi 9. Jakarta : Salemba Empat

9. Darmawan, Didit. 2013. Prinsip-prinsip perilaku organisasi. Surabaya: Pena Semesta

10.Fahmi, Irham. 2013. Etika Bisnis. Bandung : Alfabeta, CV

11.Fakhri, Ashrial Yusnar dan Marsono. 2013. Faktor yang mempengaruhi respon auditor dalam mendeteksi salah saji material sebagai akibat fraudelent financial statement (studi pada kantor akuntan publik di semarang). Volume 2 no 1. Semarang: Diponegoro Journal Of Accounting

12. Hakim, Abdul dan Anwar Hadipapo. 2015. Peran kepemimpinan dan budaya organisasi terhadap kinerja sumber daya manusia di wawotobi. Semarang : Universitas Islam Sultan Agung

13. Hall, J. A. (2001). Sistem Informasi Akuntansi. Jakarta: Salemba Empat

14. Harry Santoni . 2016. http://jabar.tribunnews.com/2016/10/22/pung utan-liar-di-sekolah-karena-lembah-dalampengawasan

15. Herman, Lisa Amelia. 2013. Pengaruh keadilan organisasi dan sistem pengendalian intern terhadap kecurangan. Padang : Universitas Negeri Padang

16. Hery. 2013. Setiap auditor harus baca buku ini. Jakarta : Gramedia

17.http://portal.bandung.go.id/pemerintahan/stru ktur-organisasi-pemerintah-kota-bandung 
18. Karyono. 2013. Forensic Fraud. Yogyakarta : CV. Andi Offset

19.Kombes Pol Hendro Pandowo. 2017. http://regional.kompas.com/ $\mathrm{read} / 2017 / 01 / 28 / 22180811 / /$ terlibat.pungli.kadis.penanaman.modal.band ung.terancam.bui.20.tahun

20.Kombes Pol Yusri Yunus . 2016. http://news.detik.com/berita-jawa-barat/d3340511/tiga-petugas-kebersihan-samsatsubang-tertangkap-basah-menjadi-calo

21. Kusumastuti, N. R. 2012. Analisis Faktorfaktor yang Berpengaruh terhadap Kecenderungan Kecurangan Akuntansi dengan Perilaku Tidak Etis Sebagai Variabel Intervening. Skripsi. Semarang: Universitas Diponogoro.

22.Latan, Hengky dan Selva Temalagi. 2013. Analisis Multivariate teknik dan aplikasi menggunakan program IBM SPSS 20.0. Edisi Kesatu. Bandung : Alfabeta

23.Lestari, dkk. 2015. Pengaruh pengendalian internal dan budaya etis organisasi terhadap kecenderungan kecurangan (fraud) pada koperasi simpan pinjam di kecamatan Buleleng. Singaraja : Universitas Pendidikan Ganesha

24. Muhammad Khoirul Anwar. 2015. http://news.detik.com/jawabarat/2811273/om budsman-serahkan-rekaman-video-praktikpungli-di-bandung-ke-ridwan-kamil

25.Muhamad Nandri Prilatama . 2016. http://jabar.tribunnews.com/2016/10/20/3bulan-penyelidikan-ridwan-kamil-pecatbeberapa-kepala-sekolah-favorit-lakukanpungli

26.Mustikasari, Dhermawati Putri. 2013. Persepsi pegawai dinas se-kabupaten batang tentang faktor-faktor yang memperngaruhi kecurangan (fraud). Semarang : Universitas Negeri Semarang

27.Pramudita, A. 2013. Analisis Fraud Di Sektor Pemerintahan Kota Salatiga. Accounting Analysis Journal, 1(3), 36-43

28. Putra Prima Perdana. 2017. http://regional.kompas.com/read/2017/ 01/28/22180811//terlibat.pungli. kadis.penanaman.modal.bandung.terancam. bui.20.tahun

29. Rahayu, Siti Kurnia dan Ely Suhayati. 2010. Auditing. Yogyakarta : Graha IImu

30.Robbins, P. Stephen dan Mery Coulter. 2010. Manajemen. Edisi 10. Jilid 1. Jakarta : Erlangga

31.Rivai, Veithzal dan Deddy Mulyadi. 2010. Kepemimpinan dan Perilaku Organisasi. Edisi ketiga. Jakarta : Rajagrafindo Persada, PT

32.Schaefer, Richard T. 2012. Sosiologi. Edisi 12. Buku 1. Jakarta : Salemba Humanika
33. Sugiyono. 2015. Metode penelitian kuantitatif kualitatif dan R\&D. Bandung : Alfabeta

34.Tika, Moh.Pabundu. 2008. Budaya Organisasi dan Peningkatan Kinerja Perusahaan. Jakarta : Bumi Aksara, PT

35.Tuanakotta, Theodorus M. 2012. Akuntansi Forensik \& Audit Investigatif. Jakarta : Salemba Empat

36. Tunggal, Amin Widjaja. 1995. Struktur Pengendalian Intern. Jakarta : Rineka Cipta, PT

37.Tunggal, Amin Widjaja. 1992. Pemerikaan Kecurangan (Fraud Auditing). Jakarta : Rineka Cipta, PT

38.Wickman, Peter M. 1991. "Deviance". HIm 85-87 dalam Encyclopedic Dictionary of Sosiology. Edisi Keempat. Diedit oleh Dushkin Publishing Group. Guilford. CT : Dushkin

39.Wilopo. 2006. Analisis Faktor-Faktor yang Berpengaruh terhadap Kecenderungan Kecurangan Akuntansi: Studi pada Perusahaan Publik dan Badan Usaha Milik Negara di Indonesia. Makalah disajikan dalam Simposium Nasional Akuntansi 9. IAI. Padang

40.Zelmianti, Riri dan Lili Anita. 2015. Pengaruh Budaya Organisasi dan peran auditor internal terhadap pencegahan kecurangan dengan pelaksanaan sistem pengendalian internal sebagai variabel intervining. Jurnal Akuntansi Keuangan dan Bisnis Vol 8. Riau : Jurnal Politeknik Caltex Riau

41.Zulkarnain, Rifqi Mirza. 2013. Faktor-faktor yang mempengaruhi terjadinya fraud di sektor pemerintahan (Studi kasus pada dinas se-kota surakarta). Semarang : Universitas Negeri Semarang

\section{Catatan :}

Artikel ini telah dipresentasikan dalam Festival Riset IImiah Manajemen dan Akuntansi Tahun 2018 (FRIMA 2018) yang diselenggarakan Oleh STIE STEMBI - Bandung Business School, dan abstraknya dimuat dalam Prosiding FRIMA 2018 dengan ISSN No 2614-6681. Selanjutnya, Penulis melakukan beberapa revisi terhadap artikel ini untuk menyempurnakan isi dan kedalaman pembahasan, untuk dapat diterbitkan dalam jurnal INTEKNA 